Kansas State University Libraries

New Prairie Press

\title{
MULTIVARIATE STATISTICAL ANALYSIS OF TERRESTRIAL INVERTEBRATE INDEX OF BIOTIC INTEGRITY
}

\author{
Bahman Shafii \\ William J. Price \\ Norm Merz \\ Timothy D. Hatten
}

See next page for additional authors

Follow this and additional works at: https://newprairiepress.org/agstatconference

Part of the Agriculture Commons, and the Applied Statistics Commons

\section{(c) (1) $\Theta($}

This work is licensed under a Creative Commons Attribution-Noncommercial-No Derivative Works 4.0 License.

\section{Recommended Citation}

Shafii, Bahman; Price, William J.; Merz, Norm; and Hatten, Timothy D. (2013). "MULTIVARIATE STATISTICAL ANALYSIS OF TERRESTRIAL INVERTEBRATE INDEX OF BIOTIC INTEGRITY," Conference on Applied Statistics in Agriculture. https://doi.org/10.4148/2475-7772.1017

This is brought to you for free and open access by the Conferences at New Prairie Press. It has been accepted for inclusion in Conference on Applied Statistics in Agriculture by an authorized administrator of New Prairie Press. For more information, please contact cads@k-state.edu. 
Author Information

Bahman Shafii, William J. Price, Norm Merz, and Timothy D. Hatten 


\title{
MULTIVARIATE STATISTICAL ANALYSIS OF TERRESTRIAL INVERTEBRATE INDEX OF BIOTIC INTEGRITY
}

\author{
Bahman Shafii and William J. Price \\ Statistical Programs, College of Agricultural and Life Sciences, University of Idaho, Moscow, Idaho \\ Norm Merz \\ Fish and Wildlife Department, Kootenai Tribe of Idaho, Bonners Ferry, Idaho
}

Timothy D. Hatten

Invertebrate Ecology Inc, Moscow, ID

\begin{abstract}
The Index of Biotic Integrity (IBI) is designed to measure the changes in ecological and environmental conditions as affected by human disturbances. In practice, the IBI is used in various ecological applications to detect divergence in biological integrity attributable to human actions. Last year during this conference, methodologies for developing an Avian Index of Biotic Integrity (A-IBI) were presented and discussed. The objective of this paper is to demonstrate the construction and statistical evaluation of a multi-metric terrestrial Invertebrate Index of Biotic Integrity (I-IBI) using the same multivariate statistical techniques. Canonical correlation analyses were utilized to select pertinent invertebrate metrics as impacted by vegetation and hydrology variables. The resulting invertebrate metrics were then ranked, according to a pre-specified scale of human disturbance, and the I-IBI scores were subsequently computed. The multivariate model, as well as the final I-IBI scores were statistically validated using independent temporal data sets. Furthermore, the sensitivity of I-IBI values was determined in order to access their reliability. The techniques are demonstrated using five years of invertebrate survey data collected from the terrestrial environments within the historic fifty-year floodplain of the Kootenai River in Northern Idaho.
\end{abstract}

\section{Introduction}

The Index of Biotic Integrity (IBI) is a multi-metric index used to detect changes in ecological conditions due to human disturbance (Kerans and Karr, 1994). IBI is the basis for detecting divergence in the biological integrity of ecosystems that are attributable to human action. The IBI should incorporate biological aspects that are sensitive to a range of human activities. Incorporation of biological attributes should be done considering individual as well as higher level assemblages (Karr, 1999). Additionally, the biotic metrics used should be selected based on their biological relevance, sensitivity to anthropogenic impact, and cost effectiveness (Andreason et al., 2001).

Traditional IBI analyses consider univariate solutions which are typically based on parametric or nonparametric correlation analyses between a set of biological metrics and a corresponding set of environmental site indices or site characteristic scores. In many cases, however, this approach may lead to no discernible patterns or correspondence with disturbance measures. Because ecological investigations 
often involve a multi-metric ecosystem with multiple community responses measured at varying dimensions, the current analyses will consider a multivariate approach for IBI construction.

The objective of this study is to present the construction and evaluation of a multi-metric terrestrial Invertebrate Index of Biotic Integrity (I-IBI) using a multivariate canonical correlation analysis. Applications of this process will be demonstrated with reference to five years of bio-monitoring surveys of terrestrial invertebrates conducted on the Kootenai River watershed in northern Idaho and northwestern Montana.

\section{Methods of Analysis}

\section{IBI Development Flow Charts}

In general, IBI construction starts with defining the human impact or disturbance level based on abiotic metrics for a selected number of sites. The site characteristics/variables are then correlated with potential biotic metrics to identify important biological variables. The expected direction of biological variables relative to disturbance are then determined and rated (ranked) on a nominal scale. The sum of these ranks is subsequently used to form the desired IBI scores. Validation and/or verification often follow the construction of the initial IBI model. This traditional process for IBI construction is depicted in Figure 1a.

Kerans and Karr (1994) extended this methodology employing principle component analysis (PCA) to identify important site characteristic variables. We expand on that idea, using canonical correlation analyses to identify both important biological as well as site characteristic variables. The process is further improved through the use of a human-centric disturbance scale for the site characteristic variables. The expected direction of biological variables is then determined from the sign of their correlation with these standardized site scores. A flow chart for this enhanced IBI methodology is given in Figure 1b. Note the application of canonical analyses differentiating the two approaches.

\section{Source and Description of the Data}

The data components included both biological metrics (invertebrate family abundance data and community diversity metrics) as well as site characteristics relating to hydrology and vegetation disturbance variables.

Trap collections were recorded for three sampling periods (i.e. rotations) from late May to mid September per site. The trap counts were subsequently rarified to 7 cups per site to standardize the data among sites. Selected sites had flood return intervals $\leq 50$ years as well as 3 rotations present in 2-3 of the years sampled (2007-2009). Taxonomic data for each site - year combination were aggregated over the 3 rotations per year and a large suite of invertebrate metrics calculated. The three annual sets of invertebrate metrics were then averaged for each site-year combination to give one value per metric for the 3 -year period set at each site ( $\mathrm{n}=33$ sites).

All invertebrate specimens collected were identified to the family level. The family level data were incorporated into over 100 family and guild metrics. These metrics were winnowed down to the fourteen invertebrate metrics selected subsequently for model evaluation based on the criteria that they be 
significantly correlated with site scores in two of the three years. The metrics included two diversity measures (ColeopCt, CollS), representing the observed counts and richness of Coleoptera (beetles) and Collembola (springtails), respectively, four guild classes (Algae_Ln, Omni_Ln, Canopy_Ln, and Soil_Ln ), representing the log of counts of the feeding groups of insects associated with algae (feeding on photosynthetic organisms), omnivores (feeding on plants and/or insects), and habitat groups for insects found in the canopy or soil (primarily living in the upper most layer of vegetation or land surface), and eight taxa classes (Carabidae, Cicadellidae, Coccoidea, Corylophidae, Formicidae, Nitidulidae, Sciaridae, Sminthuridae), representing the counts of ground beetles, leafhoppers, scale insects, hooded beetles, ants, sap-feeding beetles, fungus gnats, and globular springtails, respectively.

The hydraulic site characteristic variables considered were:

- WD_Avg - Average of water depth site scores across flood return intervals.

- SS_Avg - Average of shear stress site scores across flood return intervals.

- FD_Avg - Average of flood duration site scores across flood return intervals.

- Combined_Avg - Average of the above hydraulic site scores.

- $\quad$ FFZ - Inundation frequency site score.

- OAHD-Average of all individual hydraulic variables related site score.

Hydraulic scores were based on the proportional difference between modeled historic vs current situations at each site under a suite of flood return intervals $(1,2,5,10,25,50$-year flood return intervals).

The vegetation site characteristics considered were:

- $\quad$ Struct - Weighted average of structure site scores based on the number of structural layers, eg. Canopy, etc.

- $\quad$ Tree - Weighted average Sum of tree site scores based on the percentage of canopy cover provided by riparian associated tree species

- $\quad$ Shrub - Weighted average Sum of shrub site scores based on the percentage of canopy cover provided by riparian associated shrub species

- Weed - Weighted average Sum of weed site scores based on the percentage of canopy cover of noxious weeds

- $\quad$ RCG - Weighted average Sum of reed canarygrass (RCG) site scores based on the percentage of RCG canopy cover.

- $\quad$ Avg Rip - Simple average of the above riparian site scores

Due to the heterogeneity of the sites, the scores were weighted by the proportion of the respective cover type.

It is important to note that within the study area, the hydroelectric Libby dam is the primary and predominant source of human disturbance. Its main effect is to regulate and mitigate flooding events through controlled water releases. These management activities directly affect and change the riparian vegetation along the river. These include changes in species composition as well as succession sequences. Hence, the aforementioned vegetation variables were included to provide a relevant and encompassing measure of human disturbance.

Each hydrology and vegetation characteristic was scored with regard to human impact on a scale from 1 to 10, where 1 and 10 represent high and low impact, respectively. Scoring of hydrology and vegetation characteristics was provided by the project personnel. Scoring provides a standardized scale of disturbance, which will provide the independent variables in subsequent construction of the IBI scores. 
Site locations were selected through a random process. Initially, the Kootenai River was segmented into eight arbitrary reaches extending from Libby Dam to the Canadian border. Within each reach, sample sites were randomly generated throughout the 500-year floodplain using ArcInfo GIS (ESRI 2002). This sample was reduced by applying selection filters, such as land ownership, access, safety, less than 5 habitat types within $50 \mathrm{~m}$, and distribution throughout the reach. Once a sample site was selected from on-the-ground verification, all random points within $150 \mathrm{~m}$ were excluded from consideration to maintain independence of the point count samples. In addition, land cover classification was considered to ensure reasonable representation of land cover classes throughout the reach. A flood return interval of equal or less than 50 years was selected as this provides the most information on the regulatory effects caused by Libby dam, which was constructed 40 years ago. Although longer interval flood events do occur, they are infrequent and do not consistently capture the dynamic regulatory effects of the dam on the floodplain. A total of $n=33$ invertebrate sites were represented in the final IBI analyses. Figure 2 represents a topographical map of the invertebrate sites within the specified study area.

\section{Multivariate Analysis}

Given a multivariate data set, e.g. the set of invertebrate responses, PCA may be utilized to reduce the dimension of the data by determining one or more linear combinations of the responses (axes) that account for the largest proportion of variability in the data. The objective is to retain as few axes as possible while explaining the majority of the data variability (Morrison, 1976; James and McCulloch, 1990). The PCA axes represent lurking, subject related, underlying factors, while the coefficients (loadings) of these axes convey information on the relative importance of individual variables. These loadings will in turn provide a means for variable selection.

Similarly, given two multivariate data sets, such as the invertebrate metrics and hydrology site score variables, PCA can be utilized to assess the association between the data sets. However, canonical correlation carried out on both data sets simultaneously extends the PCA concept by computing correlation between the corresponding axes of the data sets (canonical correlation). Hence, canonical correlations analyses help define multivariate relationships, as well as provide a means for selecting both biological and site related variables concurrently.

Two separate scenarios were considered that relate the biological invertebrate metrics to either the hydrology or vegetation site characteristics. A third integrated model relating the biological metrics to a combination of the hydrologic and vegetative site score variables was also considered:

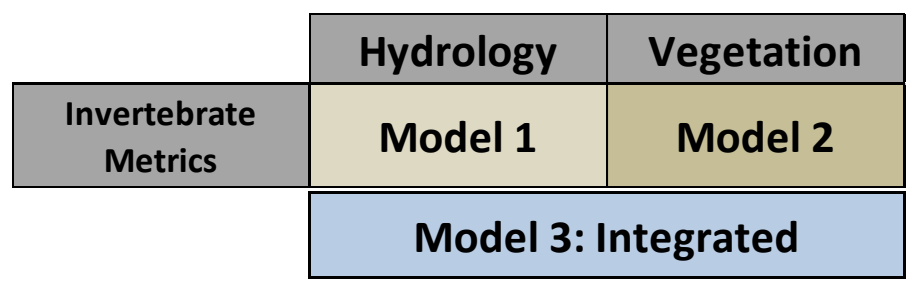

Each scenario was initiated with a full suite of respective biological and site score variables (full models). Subsequently, reduced models were constructed using backward elimination of variables in each respective full model while maintaining model integrity and canonical correlation $\geq 0.65$. The generic forms of the two reduced models are given below. 
Model 1:

$$
\left[\begin{array}{c}
\text { Algae_Ln } \\
\text { Cicadellidae } \\
\text { Coccoidea } \\
\text { Corylophidae }
\end{array}\right]=f\left(\mathrm{FD}_{\text {Avg }}, \mathrm{SS}_{\mathrm{Avg}}, \mathrm{FFZ}\right)
$$

Model 2:

$$
\left[\begin{array}{c}
\text { Omni_Ln } \\
\text { Canopy_Ln } \\
\text { Cicadellidae } \\
\text { Formicidae } \\
\text { Coccoidea } \\
\text { Corylophidae }
\end{array}\right]=\boldsymbol{f}(\text { Tree, } R C G)
$$

Reduced models were assessed using multi-metric canonical regression,

$$
\mathrm{Y}_{\text {Inv }}^{i}=\mathrm{b}_{0}+\mathrm{b}_{1} \cdot \mathrm{X}_{\text {Site }}^{i}
$$

where $\mathrm{Y}_{\text {Inv }}^{i}$ is the $\mathrm{i}^{\text {th }}$ canonical axis of invertebrate metrics, $\mathrm{X}_{\text {Site }}^{i}$ is the $\mathrm{i}^{\text {th }}$ canonical axis of site scores, and $b_{0}$ and $b_{1}$ are regression coefficients. Canonical regression provided numerical and graphical information on the multivariate relationships present.

Reduced models were further assessed through multivariate multiple regression models and diagnostics. For brevity, these results are omitted from the current presentation.

The final integrated model took the generic form:

\section{Model 3:}

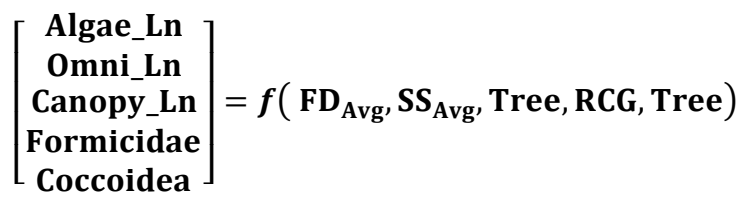

The final model encompasses five invertebrate metrics that were subsequently utilized in the construction of invertebrate IBI scores as described below.

\section{I-IBI Construction}

In order to construct the invertebrate index of biotic integrity (I-IBI), the relationships of the selected biological metrics with disturbance must be assessed. The question posed: does the metric value increase or decrease with disturbance? A decision based on the "expected direction" was suggested by Kerans and Karr (1994). While this is a viable option, it introduces subjectivity into the problem, possibly leading to inconsistency, especially if the number of selected variables is large. An alternative strategy was used in this study based on the signs of the correlation between the invertebrate metrics and 
the standardized site scores. This method gives a direct assessment of "direction". For example, if a metric were positively correlated with disturbance, then low metric values would indicate low disturbance and high values would imply association with high levels of disturbance. Negatively correlated metrics would lead to the opposite conclusions.

Utilizing the metric directionalities, the selected biological metrics were then ranked according to integrity and subsequently scored on the following ordinal scale: $1=$ very low integrity; $3=$ low integrity; $5=$ moderate integrity; $7=$ high integrity; $9=$ very high integrity using the quintiles of the variable distributions. Within each site, these ordinal component IBI values were then summed to form an overall IBI score. Hence, I-IBI is useful for relative site to site comparisons as pertinent to invertebrate metrics. It is not appropriate for determining absolute habitat or ecological condition.

\section{I-IBI Validation and Verification}

In order to avoid introducing inherent functional relatedness (circularity) into the IBI model development process, the final model should be applied to, or validated with, independent data sets. While both spatial and temporal validations are recommended (see for example, Karr, et. al, 1987, US EPA, 2002) to ensure model adequacy, only temporal validation was possible for the invertebrate data. The validation assessment provided a means to evaluate the quality and reliability of the I-IBI scores. Future verification is anticipated to include ground truthing with sites having known levels of impact and association with site scores.

Invertebrate data from 2010 and 2011 were used for the purpose of statistical validation. The validation process for each year (as well as the average of both years) encompassed data component comparison, canonical correlation validation, and bootstrap simulation.

\section{IBI Sensitivity Analysis}

Sensitivity analyses of the invertebrate I-IBI values were developed based on a comparison of potential IBI changes with respect to confidence intervals placed on the observed site I-IBIs. That is, for each site, the question was asked whether a change in an I-IBI value would lie within a specified confidence interval for that site's observed I-IBI. These results were summarized over all sites to give the proportion of sites detecting a significant level of change in I-IBI. This process was repeated over a range of possible changes in I-IBI values, as well as a range of confidence levels for the intervals.

\section{Development of IBI Confidence Intervals}

A bootstrap simulation algorithm was used to generate I-IBI distributions for each site. The bootstrap process drew a sample of size three, with replacement, from all the available data (years) for the site of interest (target site). The I-IBI value was then computed for the bootstrap sample following the same procedures described above under I-IBI-construction. That is, the invertebrate metrics for the bootstrap sample were averaged across the sampled years and the resulting mean values were then scored according to the 1, 3, 5, 7, 9 IBI scale. These scored metrics were then summed to give a bootstrap I-IBI value.

This process was repeated $\mathrm{B}=5000$ times, for each site, and the resulting distributions of bootstrap I-IBI values recorded. The distributions for each site were then summarized into two sided percentile intervals (upper and lower bounds) at various levels of confidence, e.g. 80\%, 85\%, 90\%, 95\%, and 99\% confidence. These intervals or bounds represent the range of background variability anticipated in the observed I-IBI values. 
Ideally, the bootstrap sampling process would randomly retrieve the available years of data at a given target site. However, the number of actual years present for each site was limited (1 to 3) and the resulting bootstrap distributions based on only these data were often overly discrete or even degenerate (containing only one value). To resolve this issue, a nearest neighbor algorithm was employed to identify the two nearest neighbors of the target site (defined as the Euclidean distance). The bootstrap sampling procedure described above was then applied to the target site and its two nearest neighbors (sampling with replacement was carried out from the target site and its adjacent neighbors). This ensured that the final bootstrap distributions generated over the 5000 sampling iterations were more complete.

\section{Change in IBI values}

Because the observed I-IBIs differed in magnitude, the interpretation of a fixed level of change in an I-IBI value may not be consistent from site to site. To mitigate this effect, the change in I-IBI was defined on a relative basis as the percentage of the observed IBI value (or relative precision). This allows a broader comparison of results across sites. To examine the sensitivity of the I-IBI metric, this relative precision was evaluated from $1 \%$ to $50 \%$ of the observed I-IBI.

\section{Determination of I-IBI Sensitivity}

Each observed I-IBI was altered by adding and subtracting the amount specified by a given level of relative precision. These upper and lower limits were then compared to the bounds of the bootstrap confidence intervals described above. The change was deemed as significant if:

$$
\begin{gathered}
\text { I-IBI } I_{\text {lower limit }}<\text { lower confidence bound, } \\
\text { or } \\
\mathrm{I}_{-} \mathrm{IBI}_{\text {upper limit }}>\text { upper confidence bound. }
\end{gathered}
$$

This process was carried out for every site at all combinations of relative precision and confidence. The results for each scenario were then summarized as the proportion of the 33 invertebrate sites showing significant change. These proportions were then plotted against the relative precision.

All statistical computations and graphics were carried out using the SAS (2010) software.

\section{Empirical Results}

\section{Multivariate Analysis and Model Assessment}

The first two model scenarios defined earlier relating invertebrate responses to site score variables were assessed using canonical correlation methods. Starting with a full model in each case, a backwards elimination process was employed as described above. Both models produced strong primary correlations greater than 0.80 and showed only one significant primary canonical axis (first axis for both models: $\mathrm{p}<0.0001$ ). Specific results for the first axis of the final reduced models are given in Table 1 . Model 1, relating invertebrate metrics and hydrologic scores, produced a canonical correlation of $\mathrm{R}=0.87$. The invertebrate components selected included guild as well as abundance measures. The hydrologic components selected were overall measures of inundation and those related to shear stress and flood duration. The corresponding invertebrate metrics - vegetation scenario, Model 2, produced additional guild and abundance measures, corresponding to the vegetative scores for trees and reed canarygrass 
$(\mathrm{R}=0.84)$. In both cases, the standardized coefficients were deemed strong enough to warrant retention in the respective models.

Given the strength of the two model scenarios and their commonalities among site scores, a third integrated model, encompassing all selected invertebrate measures and corresponding hydrologic and vegetative score measurements was assessed using the same backwards selection process. The final results for this integrated model are shown in Table 2. One canonical axis was highly significant and accounted for approximately $85 \%$ of the data variability. The canonical correlation along this axis was very strong at 0.91 . The remaining axes, while moderately significant, were considered to be of limited importance for the goal of IBI construction. Considering the primary axis, the final integrated model retained two hydrologic score variables: FD_Avg, and SS_Avg, as well as the vegetation score variables: Tree and RCG. Invertebrate responses included three guild and two taxa classes, with the standardized coefficients showing the relative and contrasting importance of Cicadellidae and Formicidae. Model 3 successfully reduces the dimension of the problem by retaining 5 relevant invertebrate metrics out of an initial set of 14 (65\% reduction). This was consistent with the avian model where the reduction in the total number of avian metrics was $60 \%$.

One goal of IBI development is to reduce the dimension of the problem to more manageable levels. For example, in Kimberling, et al, (2001), 57 invertebrate metrics were initially evaluated to measure human disturbance in the shrub-steppe region of Eastern Washington, of which only eight were used for the construction of the terrestrial IBI. Model 3 successfully follows this precedent, reducing the number of relevant invertebrate metrics from 14 down to 5. Incorporation of multiple invertebrate measures, in addition to a variety of site characteristics, provides strong improvement to the overall multivariate relationship. Table 3 summarizes the structure and results of all three scenarios. Combining the hydrologic and vegetative scenarios into an overall integrated canonical model provides the strongest relationship between invertebrate metrics and site characteristics. Given these results, the invertebrate metrics selected for the integrated model were considered as good candidates for the construction of an IIBI.

\section{I-IBI Construction}

Before an IBI can be computed, the nature of the relationship between the selected variables and human disturbance must be determined, answering the question: does the selected biological measure increase or decrease with disturbance? Kerans and Karr (1994) suggest using expert opinion to determine the 'expected' direction, however, it is often difficult to find consensus among the experts. In addition, their recommendations may render contradictory results, and be viewed as subjective and unclear.

As an alternative, a multivariate approach can be used through either the sign of the respective canonical coefficients or through examination of the sign of the correlations between the biological variables and the site characteristic scores. Because site scores have been designed to measure human disturbance based on a consistent and common scale, the second method, based on correlations, provides a more logical and objective means for determining the specified response direction. Table 4 lists the correlations between the selected invertebrate metrics and the corresponding site score measures. Summarizing across this table, the percentage of positive or negative correlations can be used to determine the direction of each invertebrate response relative to human disturbance. Thus, only one response, Algae_ln shows an overall positive correlation, while the remaining four indicate a negative association. 
Within each site, the selected invertebrate responses are then individually scored into predetermined habitat integrity classes based on the direction of the response. Accordingly, the defined classes should have a sufficient range such that a good definition of the final I-IBI score may be obtained, while limiting the number of classes to avoid applying or implying too much precision to the problem. In this case, five classes were chosen: 1 - Very Low Integrity, 3 - Low Integrity, 5 - Moderate Integrity, 7 - High Integrity, and 9 - Very High Integrity. This is similar to classification definitions previously used by other researchers (see for example Karr et al, 1987; Fore and Karr, 1996). If the response distribution is symmetric, class assignment may be based on the response percentiles. When non-symmetric distributions are present, however, expert opinion may be necessary to determine class assignment. Figure 4 illustrates the distributions, I-IBI score categories and the assigned directions for the five invertebrate metrics. In this example, class assignments were carried out using distribution percentiles. It is important to note that the class assignment in I-IBI construction is rather subjective, and hence, the resulting measures of biotic integrity are only meant to be interpreted in relative terms among the available sites.

Following class assignment, the overall I-IBI score is computed by summing the scored invertebrate metrics within each site. Larger values of the I-IBI score represent higher levels of biotic integrity, while smaller values represent lower levels of biotic integrity. Table 5 presents the final I-IBI scores and the component class assignments for all invertebrate sites. In addition, the canonical site score, rescaled from 1 to 10 , is also given. The I-IBI values range from a minimum of $5\left(5^{*} 1=5\right)$ to a potential maximum of $45\left(5^{*} 9=45\right)$. The observed minimum and maximum values for the I-IBI score in this case are 5 and 41, respectively. It is important to note that the aforementioned I-IBI values indicate the relative level of invertebrate integrity, and do not measure an absolute level of integrity. Hence, one may conclude that one site is more suited for supporting the invertebarte community compared to another site based on a higher value of I-IBI, but not that the specified site is optimal.

The correspondence between the invertebrate IBI measures and the scaled canonical site score (indicating site characteristics) is shown in Figure 5. This relationship is positive ( $\mathrm{R}=.58)$, indicating that relatively higher I-IBI values are associated with higher site integrity values.

One means of visualizing the I-IBI values and their spatial arrangements is using a topographical map. Figure 6 gives a map representing I-IBI values along the Kootenai River. Green colored sites indicate higher IBI values, while yellow and red colored sites denote moderate and low IBI values, respectively. It is evident that some clusters of sites have generally higher or lower invertebrate integrity, likely due to the "grouping" of superior or inferior habitat conditions. There seems to be a higher proportion of good and intermediate sites in the Canyon and Braided reaches than in the Meander, as expected, while there are more poor condition sites in the Meander reach. As it was the case for avian communities, the diverse spatial pattern may be related to the resiliency of vegetation communities buffering the impacts to hydraulic alterations.

\section{I-IBI Temporal Validation}

Temporal validation of the I-IBI was based on data collected in the years 2010 and 2011 at the same sites used for building the invertebrate model. The same validation methods used for the avian model were applied to the invertebrate model and the underlying data. A comparison of each invertebrate response from the model and validation data indicated a high degree of similarity between the two. Three of the responses showed no significant difference in average value, with cocoididae and the canopy guild class having only a marginally different mean value ( $\mathrm{p}=0.05$ and 0.06 , respectively). Overall, the 
invertebrate values in the combined 2010, 2011 dataset were similar to the corresponding values measured in 2007-2009.

Model 3 was then applied to the combined validation data. An overlaid plot of the primary canonical axis from the 2007-2009 data and the 2010, 2011 combined validation data is given in Figure 7. The validation dataset displayed the same positive trend as seen in the original canonical analysis. Although an increase is evident in the 2010, 2011 combined data, the two datasets matched very well.

As a final assessment, a set of I-IBI validation residuals was computed. Since a measure of IIBI variability was unavailable, a bootstrap simulation procedure was used to compute the observed 20072009 simulated I-IBI values, assuming years as replication. For each observation site, three observations for each invertebrate response were uniformly selected with replacement from the available years. These responses were then averaged and scored as described above to form a bootstrap I-IBI value. A residual

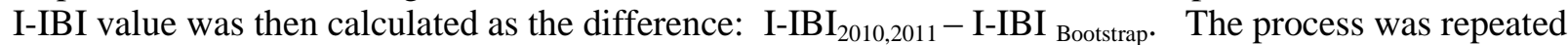
$\mathrm{B}=1,000$ times and the resulting residual I-IBI values were evaluated. A plot of the residuals over site (arranged from upstream to downstream) is shown in Figure 8. No trend was evident and the overall pattern was random and indicated no systematic differences from the 2007-2009 values. Also, the mean residual value was not significantly different from zero $(\mathrm{p}=0.7780)$. The I-IBI values appear to be temporally stable within the specified time frame.

\section{I-IBI Sensitivity}

In Figure 9, the proportions of sites detecting a significant change in invertebrate IBI are given for five confidence levels ranging from 80 to $99 \%$, with a reference line shown at a relative precision of $20 \%$. As depicted from the figure, this level of precision will detect a change in IBI for $78 \%$ of the sites with a $95 \%$ confidence coefficient. In comparison, a confidence coefficient of $80 \%$ would detect a change in more than $90 \%$ of the sites. Because higher levels of relative precision will have increased proportions of detection, we can generalize that a change in invertebrate IBI values of at least $20 \%$ can be detected with high confidence.

\section{Avian and Invertebrate IBI Comparison}

For comparative (and not inferential) purposes, the final avian IBI (A-IBI), published in the 2012 Applied Statistics in Agriculture proceedings (Shafii, et al, 2012) and the I-IBI scores developed here are represented in Table 6 for the sites that were in common among the avian and invertebrate data $(\mathrm{n}=31)$. The avian sensitivity plot developed using the same methodology as that described for the invertebrate data above, is given in Figure 10. Generally, it appears that avian and invertebrate IBI values follow each other well. Additionally, the canonical site scores, reflecting human disturbance relative to each data set, are fairly similar. While there is not an exact correspondence between the avian and invertebrate values, this may indicate an expected pattern since invertebrates are more likely to respond quickly to temporary, local conditions, such as flood events. In contrast, the bird community is more mobile, relying on vegetation for nesting and foraging which takes time to develop. However, birds can and do change their use patterns in response to temporary events, but generally these changes are not as rapid or dramatic as invertebrates. Therefore, it is expected that changes in site condition would be first detected in the insect community with a lag time before being detected in the avian community. Hence, it is not surprising that the IBI scores vary between these communities, but it is reassuring that the scores are indicating similar conditions at the same sites. 
The avian IBI analysis shows a higher level of sensitivity than that of the invertebrate data. The avian data are able to detect a $15 \%$ change in IBI values with high confidence, while the invertebrate counterpart shows similar sensitivity only at larger relative precisions of $20 \%$ or more.

\section{Concluding Remarks}

The multivariate analyses of the invertebrate data provided an enhanced IBI methodology and produced reliable IBI scores for the specified invertebrate sites within the project. The selected invertebrate metrics provided both lower and higher level representations of invertebrate data. The final consolidated model and the associated I-IBI scores were statistically validated using additional years, and produced reliable results. The I-IBI values showed a reasonable correlation to the scaled canonical site score indicating a good representation of invertebrate site integrity. The invertebrate results reported here were not as definitive as those shown previously for the avian IBI. However, both avian and invertebrate IBI models could be extended to new sites in adjacent areas to monitor biotic community responses to environmental changes such as river restoration efforts.

\section{Acknowledgement}

The authors would like to thank the Kootenai Tribe of Idaho for managing and coordinating the Operational Loss Project, and the Bonneville Power Administration for provision of funding.

\section{References}

Andreasen , J.K, R. V. O’Neill , R. Noss, and N. C. Slosser. 2001. Considerations for the development of a terrestrial index of ecological integrity. Ecological Indicators 1: 21-35.

Environmental System Research Institute (ESRI) 2002. ArcGIS 8.3. Redlands, California.

Fore, L.S. and J. R. Karr. 1996. Assessing invertebrate responses to human activities: evaluating alternative approaches. Journal of North America Benthological Society 15(2): 212-231.

Hill, M.O. (1973). Diversity and evenness: a unifying notation and its consequences. Ecology, 54, 427432.

James, F.C. and C. E. McCulloch. 1990. Multivariate analysis in ecology and systematics. Annual review of Ecology and Systematics 21:129-166.

Karr, J.R. 1999. Defining and measuring river health. Freshwater Biology 41: 221-234.

Karr, J.R., P. R. Yant, and K. D. Fausch. 1987. Spatial and temporal variability of the index of biotic integrity in three Midwestern streams. Transactions of the American Fisheries Society 116:1-11.

Kerans, B.L. and J. R. Karr. 1994. A benthic index of biotic integrity (B-IBI) for the rivers of the Tennessee valley. Ecological Applications 4(4): 768-785.

Kimberling, D.N., J. R. Karr and L. S. Fore. 2001. Measuring human disturbance using terrestrial invertebrates in the shrub-steppe of eastern Washington (USA). Ecological Indicators 1: 63-81. 
Marcot, B.G. and M.Vander Heyden. 2001. Chapter 6: Key ecological functions of wildlife species. Pages168-186 in D.H.Johnson and T.A.O'Neil. 2001, Managing Directors. Oregon State University Press, Corvaillis, OR. 736pp.

Morrison, D.F. 1976. Multivariate Statistical Methods. Second Edition, McGraw-Hill Book Company, New York, USA.

Pielou, E.C. 1977. Mathematical ecology. Wiley-Interscience Publ., NY. 385 pp.

SAS Institute Inc. 2010. SAS Online Doc® 9.3. Cary, NC: SAS Institute Inc.

Shafii, B., W. J. Price, N. Merz, and D. Bergeron. 2012. Multivariate statistical analysis of avian index of biotic integrity. In Proceedings: Applied Statistics in Agriculture, Kansas State University, Manhattan, Kansas, pp. 13-35.

U.S. EPA. 2002. Methods for evaluating wetland condition: Biological assessment methods for birds. EPA-822-R-02-023, EPA Office of Water, Washington, DC. 
(A) Model 1

\begin{tabular}{|c|c|}
\hline $\begin{array}{c}\text { Invertebrate } \\
\text { Metric }\end{array}$ & Coefficient \\
\hline ALGAE_In & 0.58 \\
\hline CICADELLIDAE & 0.84 \\
\hline COCCOIDEA & -0.74 \\
\hline CORYLOPHIDAE & -0.54 \\
\hline
\end{tabular}

\begin{tabular}{|c|c|}
\hline $\begin{array}{c}\text { Hydraulic } \\
\text { Measure }\end{array}$ & Coefficient \\
\hline SS_ave & -0.86 \\
\hline FD_ave & $\mathbf{1 . 0 5}$ \\
\hline FFZ & 0.87 \\
\hline
\end{tabular}

(B) Model 2

\begin{tabular}{|c|c|}
\hline $\begin{array}{c}\text { Invertebrate } \\
\text { Metric }\end{array}$ & Coefficient \\
\hline OMNI_Ln & -2.01 \\
\hline CANOPY_LN & 0.62 \\
\hline CICADELLIDAE & -0.6534 \\
\hline FORMICIDAE & 1.5346 \\
\hline COCCOIDEA & -0.3964 \\
\hline CORYLOPHIDAE & $\mathbf{0 . 3 2 1 1}$ \\
\hline
\end{tabular}

\begin{tabular}{|c|c|}
\hline $\begin{array}{c}\text { Vegetation } \\
\text { Measure }\end{array}$ & Coefficient \\
\hline Tree & 0.85 \\
\hline RCG & 0.49 \\
\hline
\end{tabular}

Table 1. Final reduced canonical models for two invertebrate, site characteristic scenarios: A) invertebrate metrics and hydrologic scores, B) invertebrate metrics and vegetative scores. Only the coefficients and correlations for the first canonical axes are shown.

\begin{tabular}{|r|c|c|c|r|}
\hline Axis & $\begin{array}{c}\text { Canonical } \\
\text { Correlation }\end{array}$ & Eigenvalue & Proportion & p-value \\
\hline 1 & 0.91 & 5.13 & 0.85 & $<.0001$ \\
\hline 2 & 0.57 & 0.49 & 0.94 & 0.0637 \\
\hline 3 & 0.43 & 0.23 & 0.97 & 0.1473 \\
\hline 4 & 0.37 & 0.16 & 1.00 & 0.1344 \\
\hline
\end{tabular}

\begin{tabular}{|c|c|}
\hline $\begin{array}{c}\text { Invertebrate } \\
\text { Metric }\end{array}$ & Coefficient \\
\hline ALGAE_In & 0.55 \\
\hline OMNI_Ln & -1.30 \\
\hline CANOPY_LN & 0.53 \\
\hline FORMICIDAE & 0.95 \\
\hline COCCOIDEA & -0.66 \\
\hline
\end{tabular}

\begin{tabular}{|c|c|}
\hline $\begin{array}{c}\text { Site } \\
\text { Measure }\end{array}$ & Coefficient \\
\hline SS_ave & 0.91 \\
\hline FD_ave & -0.26 \\
\hline Tree & 0.71 \\
\hline RCG & 0.70 \\
\hline
\end{tabular}

Table 2. The final integrated canonical model for invertebrate metrics as a function of hydrologic and vegetative site scores. Only the coefficients and correlation for the first axis are shown. 


\begin{tabular}{|c|c|c|c|c|l|l|}
\cline { 3 - 7 } \multicolumn{2}{c|}{} & \multicolumn{2}{c|}{ Number of Final Components } & \multicolumn{2}{c|}{ Canonical Correlations } \\
\hline Model & Description & Metrics & Hydraulic & Vegetation & Full Model & Red. Model \\
\hline Model 1 & Hydro - Metrics & 4 & 3 & & 0.92 & 0.87 \\
\hline Model 2 & Veg - Metrics & 6 & & 2 & 0.94 & 0.84 \\
\hline Model 3 & Integrated & 5 & 2 & 2 & 0.96 & 0.91 \\
\hline
\end{tabular}

Table 3. Summary table representing the reduced invertebrate canonical models for the two model scenarios and the final integrated model.

\begin{tabular}{|c|c|c|c|c|c|c|}
\hline & \multirow[b]{2}{*}{ SS_Avg } & \multirow[b]{2}{*}{ FD_Avg } & \multirow[b]{2}{*}{ Tree } & \multirow[b]{2}{*}{ RCG } & \multicolumn{2}{|c|}{ Metric Direction } \\
\hline & & & & & $\% \quad(+)$ & $\%$ \\
\hline ALGAE_In & 0.40 & 0.46 & 0.48 & 0.04 & 100.00 & 0.00 \\
\hline OMNI_Ln & -0.02 & -0.05 & -0.55 & -0.20 & 0.00 & 100.00 \\
\hline CANOPY_LN & -0.29 & -0.21 & -0.39 & -0.10 & 0.00 & 100.00 \\
\hline FORMICIDAE & 0.04 & 0.01 & -0.39 & -0.01 & 50.00 & 50.00 \\
\hline COCCOIDEA & -0.11 & -0.49 & -0.41 & -0.24 & 0.00 & 100.00 \\
\hline
\end{tabular}

Positive Correlation

Negative Correlation

Table 4. Correlations among the selected invertebrate responses and the hydrologic and vegetative site scores. Four responses indicated a negative overall association, while one displayed a positive association. 


\begin{tabular}{|c|c|c|c|c|c|c|c|}
\hline Site & ALGAE_Ln & OMNI_Ln & CANOPY_Ln & FORMICIDAE & COCCOIDEA & IBI & Site Rank \\
\hline 1018 & 5 & 3 & 5 & 5 & 3 & 21 & 4.69 \\
\hline 1023 & 7 & 7 & 7 & 9 & 7 & 37 & 4.78 \\
\hline 1078 & 3 & 3 & 3 & 3 & 5 & 17 & 3.15 \\
\hline 1093 & 7 & 3 & 7 & 3 & 5 & 25 & 4.82 \\
\hline 1128 & 5 & 5 & 5 & 5 & 7 & 27 & 7.83 \\
\hline 1135 & 9 & 5 & 5 & 5 & 7 & 31 & 8.13 \\
\hline 1185 & 7 & 5 & 5 & 7 & 5 & 29 & 4.51 \\
\hline 1189 & 9 & 5 & 7 & 5 & 5 & 31 & 10.00 \\
\hline 2052 & 9 & 7 & 7 & 7 & 7 & 37 & 5.92 \\
\hline 4005 & 9 & 5 & 9 & 3 & 5 & 31 & 6.91 \\
\hline 5051 & 7 & 7 & 9 & 7 & 7 & 37 & 7.05 \\
\hline 6010 & 3 & 7 & 3 & 5 & 7 & 25 & 8.86 \\
\hline 6181 & 7 & 9 & 7 & 7 & 3 & 33 & 7.19 \\
\hline 6183 & 3 & 9 & 3 & 7 & 3 & 25 & 4.69 \\
\hline 6197 & 5 & 7 & 5 & 7 & 7 & 31 & 7.98 \\
\hline 6201 & 5 & 9 & 9 & 9 & 7 & 39 & 9.39 \\
\hline 6202 & 7 & 9 & 9 & 9 & 7 & 41 & 9.31 \\
\hline 6205 & 9 & 9 & 9 & 7 & 7 & 41 & 9.38 \\
\hline 7005 & 1 & 5 & 7 & 5 & 3 & 21 & 1.80 \\
\hline 7103 & 3 & 3 & 3 & 3 & 1 & 13 & 1.86 \\
\hline 7205 & 7 & 1 & 1 & 1 & 1 & 11 & 3.39 \\
\hline 7207 & 9 & 3 & 1 & 3 & 3 & 19 & 5.41 \\
\hline 7208 & 9 & 3 & 7 & 3 & 7 & 29 & 7.86 \\
\hline 7308 & 3 & 1 & 3 & 1 & 1 & 9 & 1.00 \\
\hline 8004 & 1 & 3 & 1 & 3 & 3 & 11 & 5.94 \\
\hline 8022 & 1 & 1 & 1 & 1 & 1 & 5 & 4.44 \\
\hline 8103 & 5 & 9 & 5 & 9 & 1 & 29 & 5.42 \\
\hline 8407 & 3 & 1 & 1 & 1 & 7 & 13 & 6.45 \\
\hline 8512 & 5 & 1 & 1 & 1 & 3 & 11 & 5.15 \\
\hline 8521 & 1 & 1 & 1 & 1 & 1 & 5 & 5.47 \\
\hline 8654 & 1 & 1 & 3 & 1 & 5 & 11 & 4.10 \\
\hline 8744 & 3 & 7 & 9 & 9 & 7 & 35 & 3.47 \\
\hline 8988 & 3 & 7 & 3 & 9 & 1 & 23 & 2.83 \\
\hline
\end{tabular}

Table 5. The computed I-IBI values for all sites along with their component IBI classifications and the corresponding scaled canonical site score. 


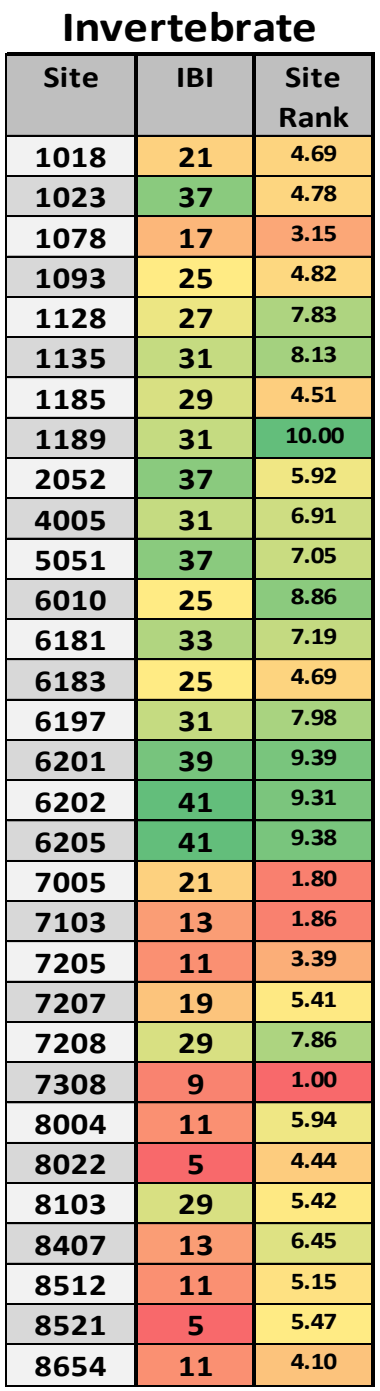

\section{Avian}

\begin{tabular}{|c|c|}
\hline IBI & $\begin{array}{c}\text { Site } \\
\text { Rank }\end{array}$ \\
\hline 50 & 5.1 \\
\hline 38 & 5.1 \\
\hline 44 & 4.6 \\
\hline 48 & 5.0 \\
\hline 38 & 6.1 \\
\hline 34 & 7.5 \\
\hline 40 & 5.9 \\
\hline 46 & 5.3 \\
\hline 46 & 5.7 \\
\hline 36 & 5.1 \\
\hline 26 & 5.9 \\
\hline 30 & 6.4 \\
\hline 48 & 6.4 \\
\hline 30 & 3.9 \\
\hline 44 & 5.9 \\
\hline 52 & 8.5 \\
\hline 54 & 8.2 \\
\hline 56 & 7.9 \\
\hline 28 & 3.1 \\
\hline 26 & 3.1 \\
\hline 34 & 2.9 \\
\hline 38 & 5.0 \\
\hline 54 & 7.4 \\
\hline 32 & 2.8 \\
\hline 36 & 6.5 \\
\hline 44 & 5.0 \\
\hline 36 & 4.4 \\
\hline 40 & 8.0 \\
\hline 32 & 5.8 \\
\hline 44 & 6.0 \\
\hline 48 & 5.7 \\
\hline
\end{tabular}

Table 6. Comparison of the avian and invertebrate IBI values along with the respective standardized canonical site scores. 


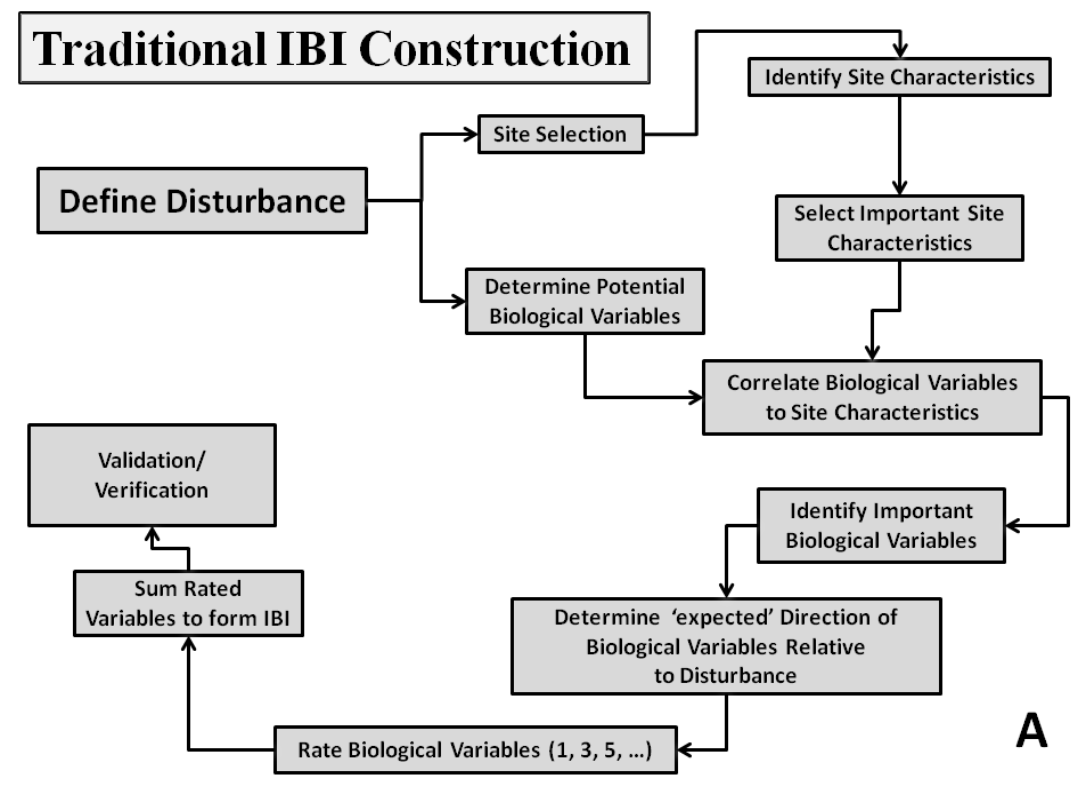

\section{Enhanced IBI Construction}

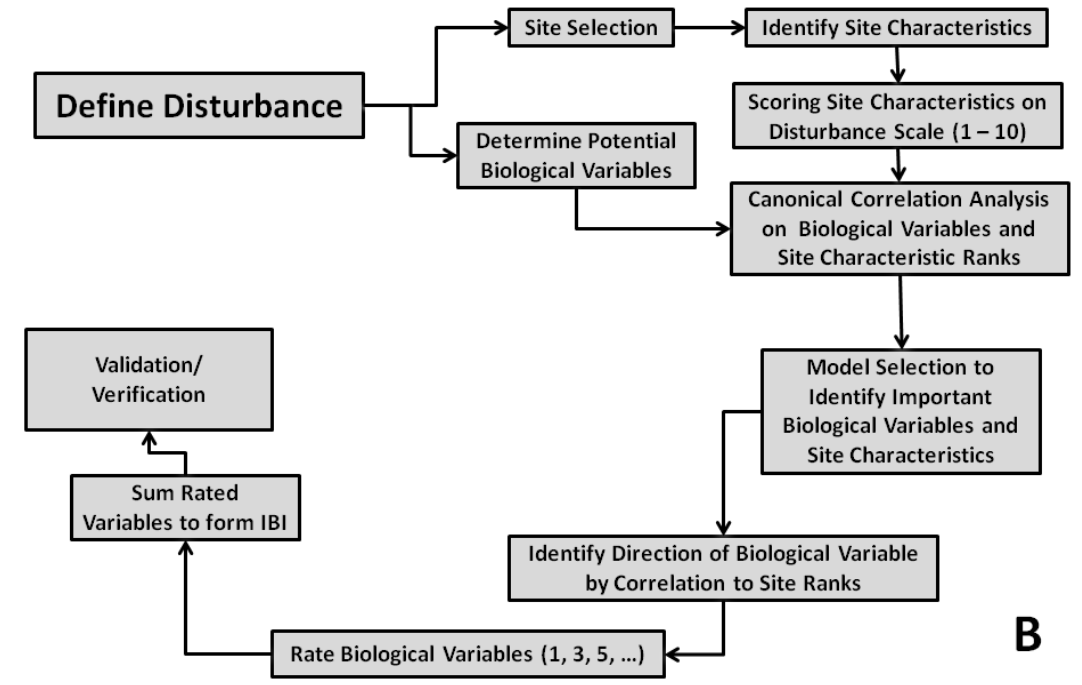

Figure 1. The traditional (A) and enhanced (B) flow charts for IBI construction. 


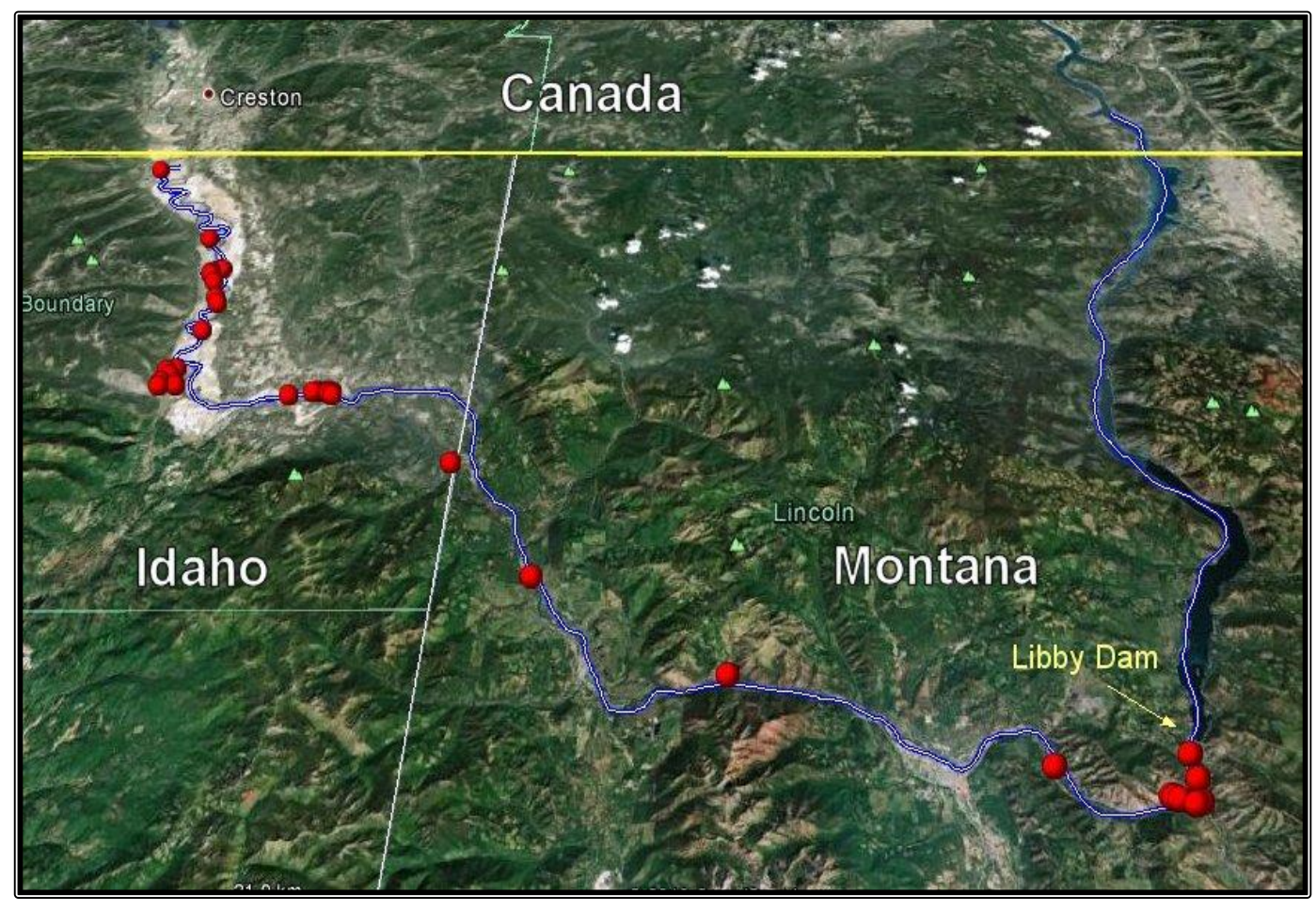

Figure 2. The 33 invertebrate sampling sites located along the Kootenai River in Idaho and Montana. 


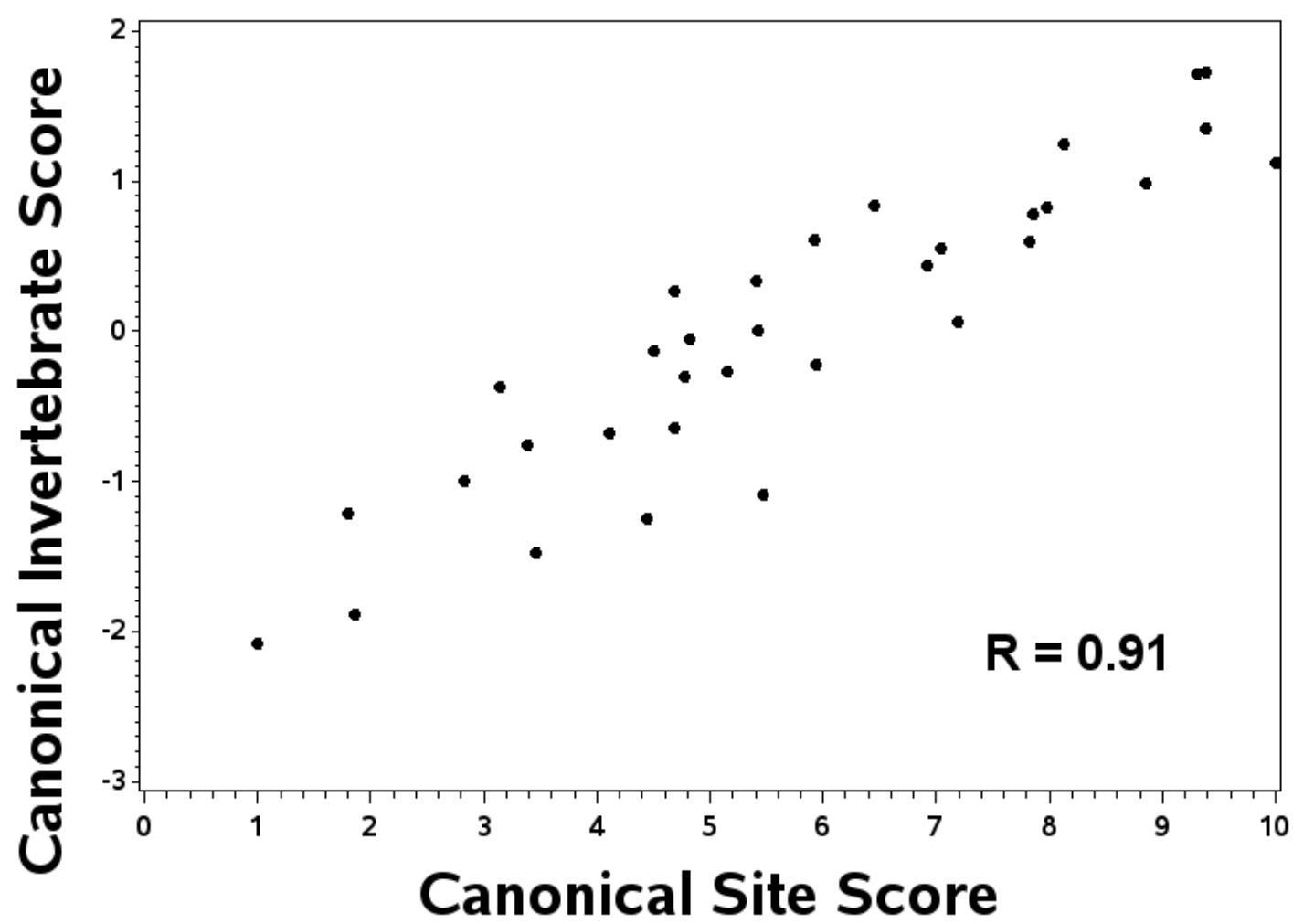

Figure 3. The primary canonical relationship between invertebrate responses and hydrologic and vegetative site characteristic scores. 


\section{Negative Direction Metrics}

Canopy Ln

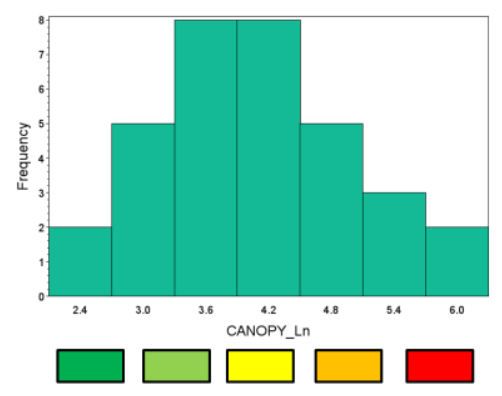

Formicidae

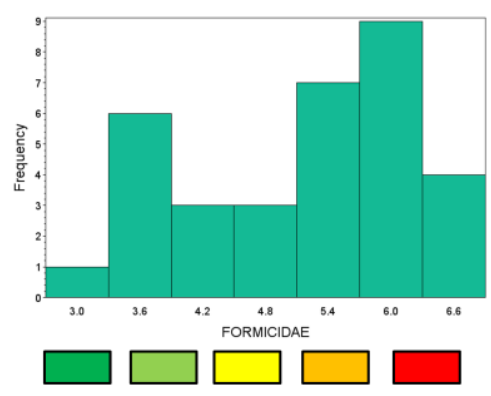

Coccoidae

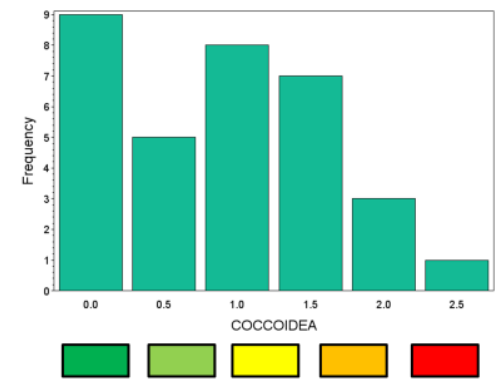

Omni Ln

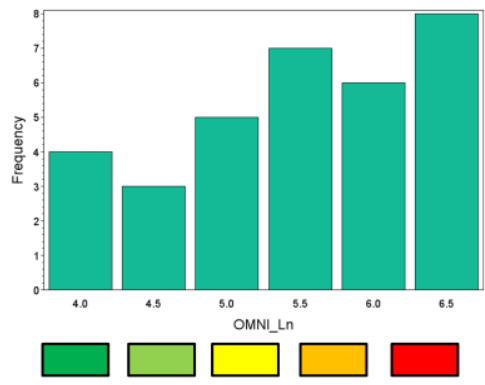

\section{Positive Direction Metrics}

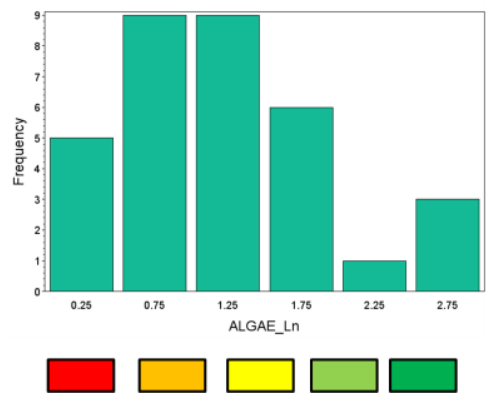

Very Low Integrity

Low Integrity

Moderate Integrity

High Integrity

Very High Integrity

Figure 4. Response distributions for the five selected invertebrate metrics. Four were negatively associated with site scores (A) and one measure was positively associated with site scores (B). 


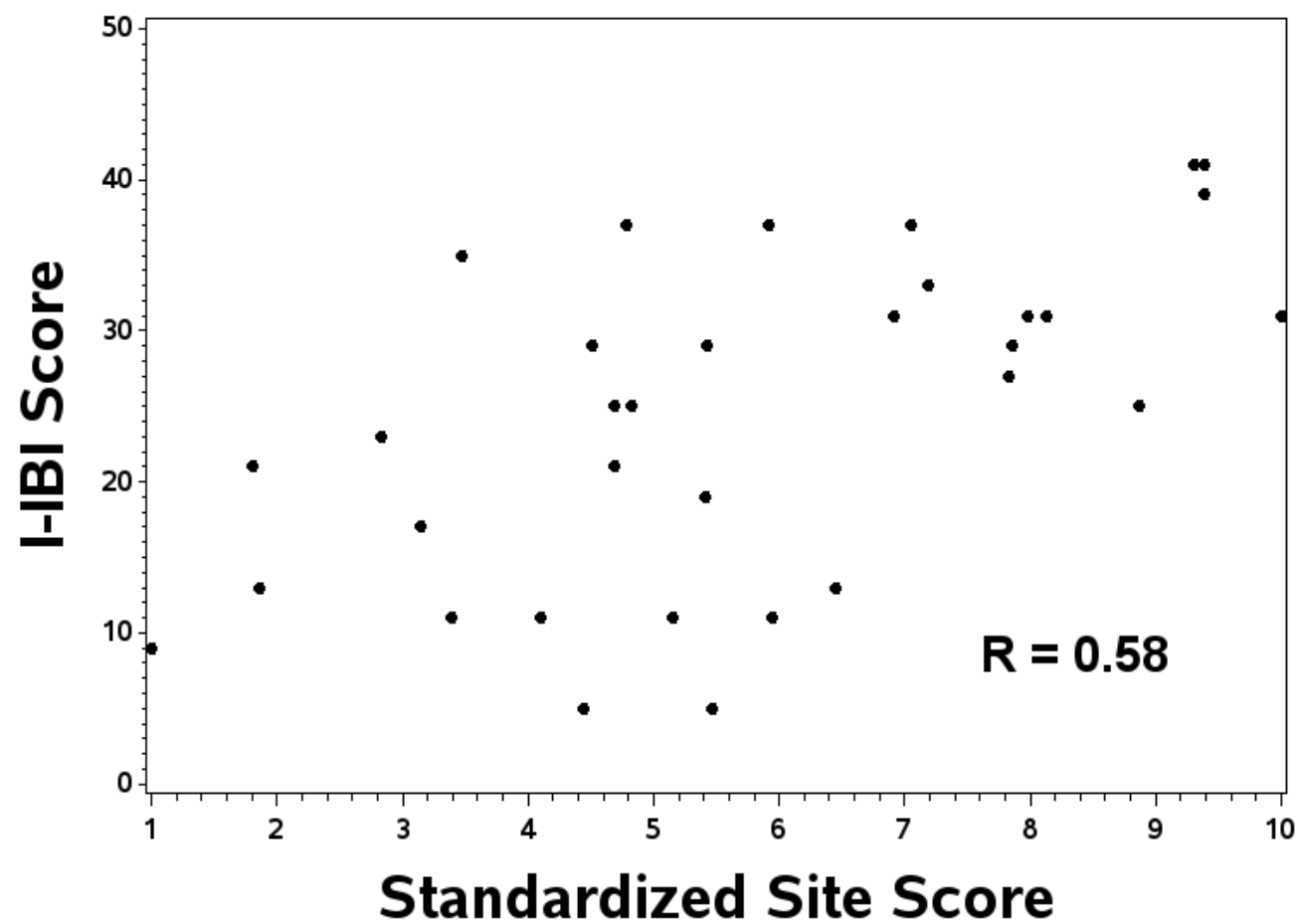

Figure 5. The association between the computed I-IBI and the standardized canonical site scores.

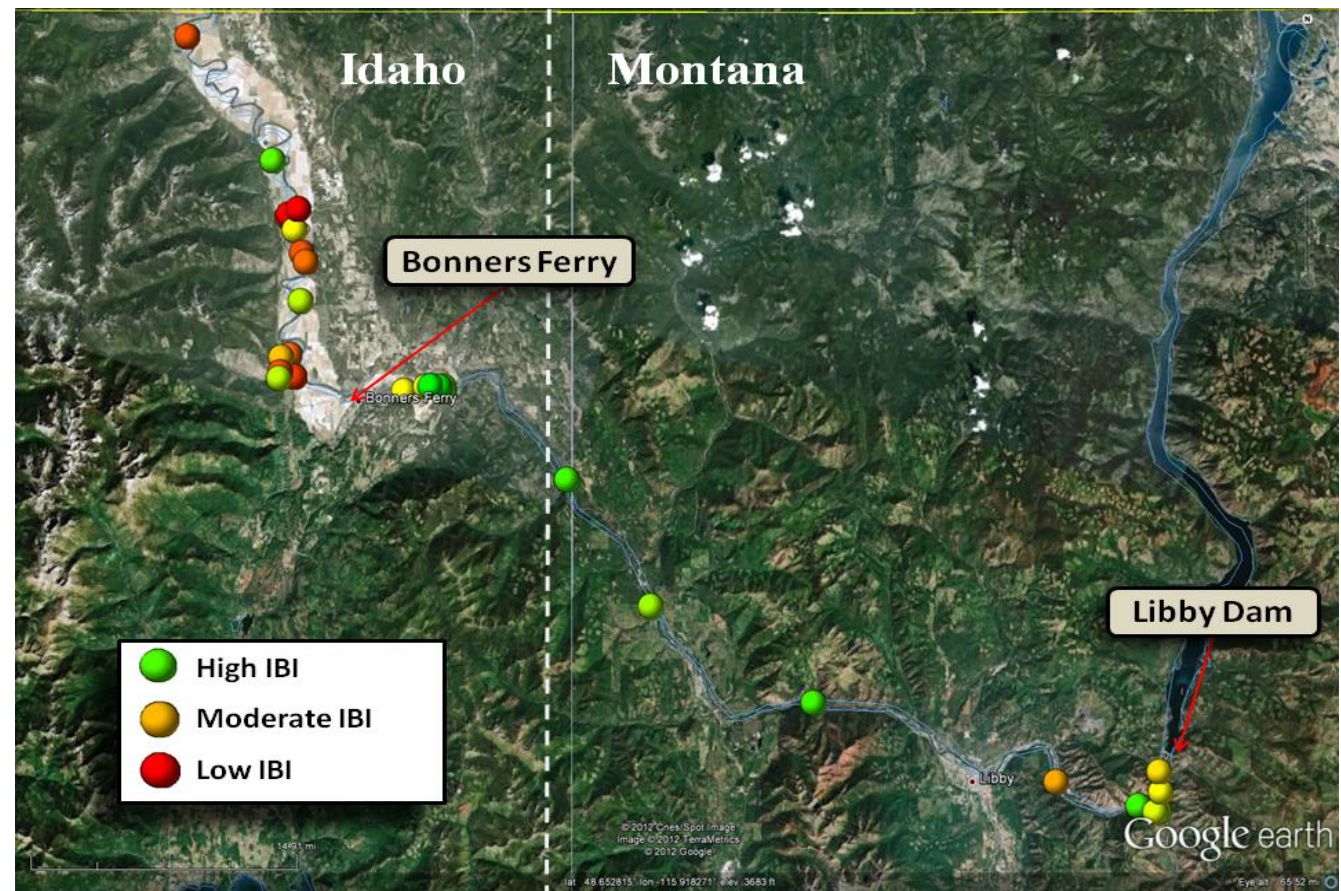

Figure 6. Graphical representation of I-IBI intensity along the Kootenai River. Green markers indicate high I-IBI values, yellow represent moderate I-IBI values and red markers show low I-IBI values. 


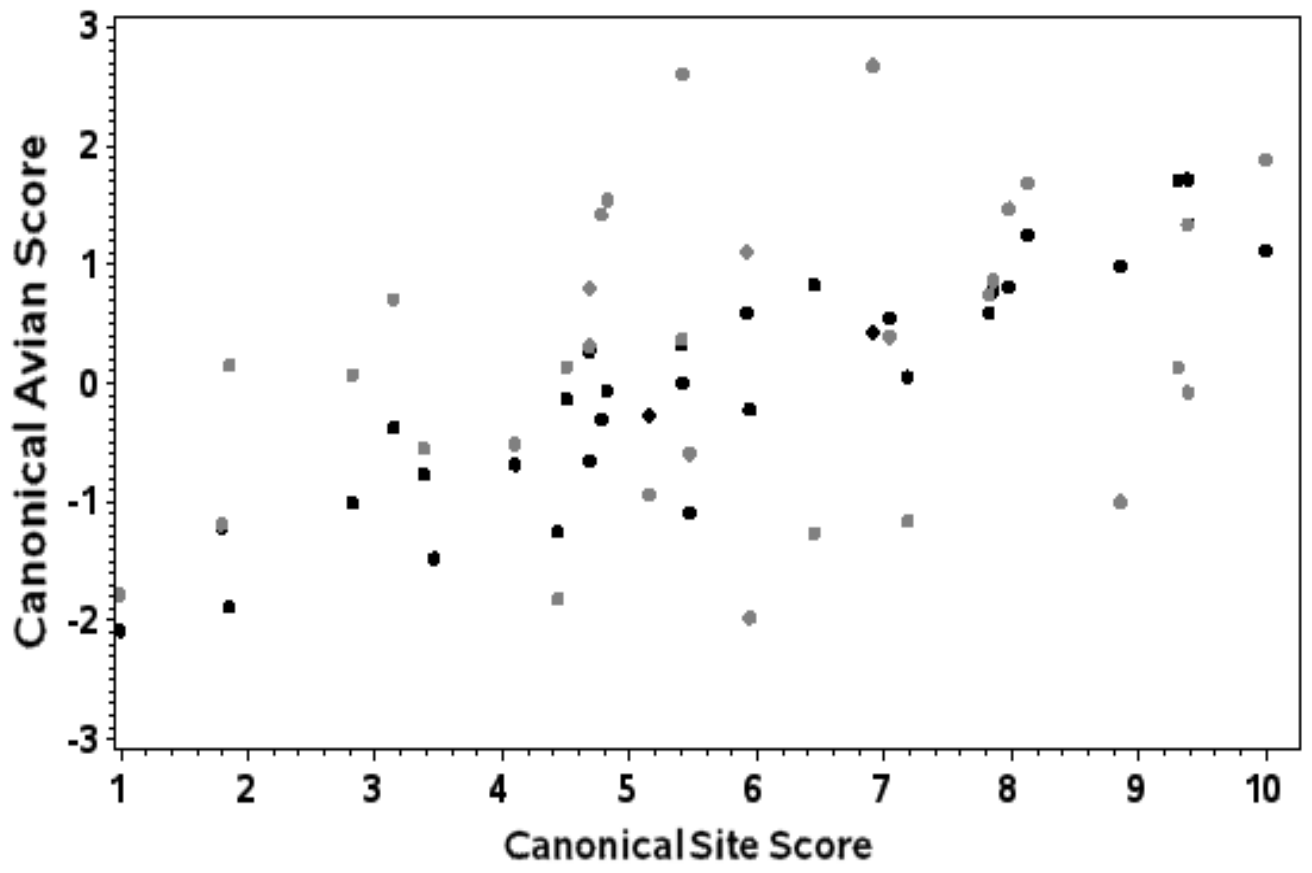

Figure 7. Comparison of the canonical relationship of the 2007-2009 data (gray dots) and the 2010, 2011 data (black dots).

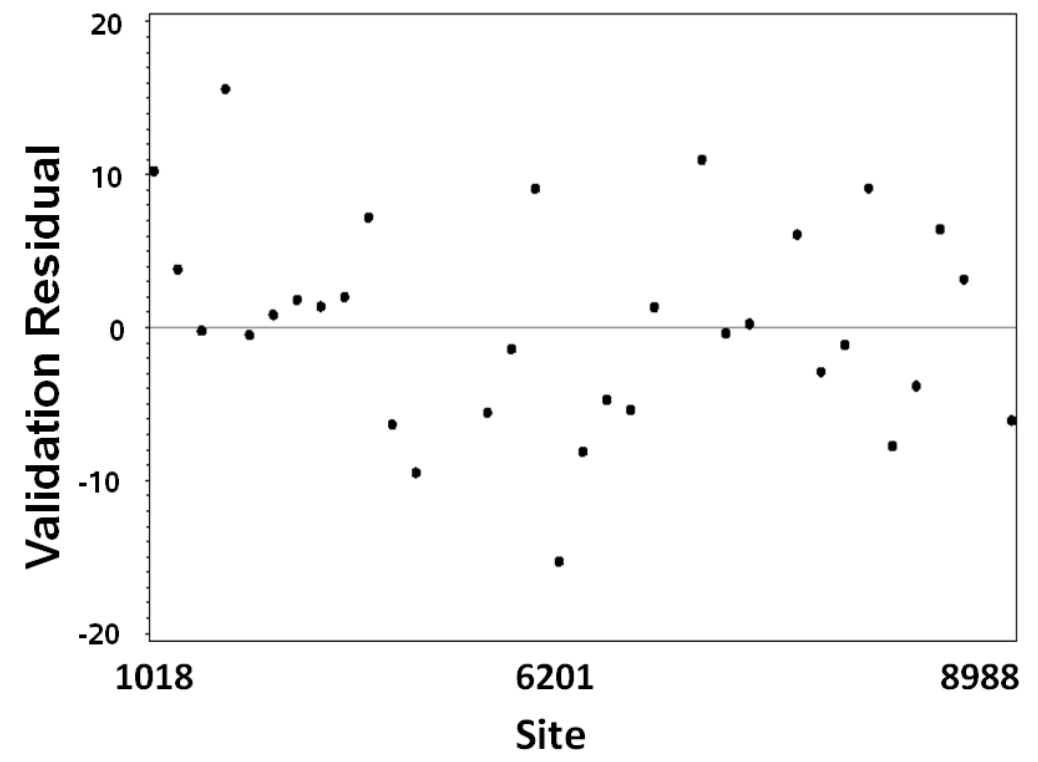

Upstream

Downstream

Figure 8. Temporal I-IBI validation residuals plotted versus sampling site ID arranged in spatial order along the Kootenai River. 
IBI Sensitivity

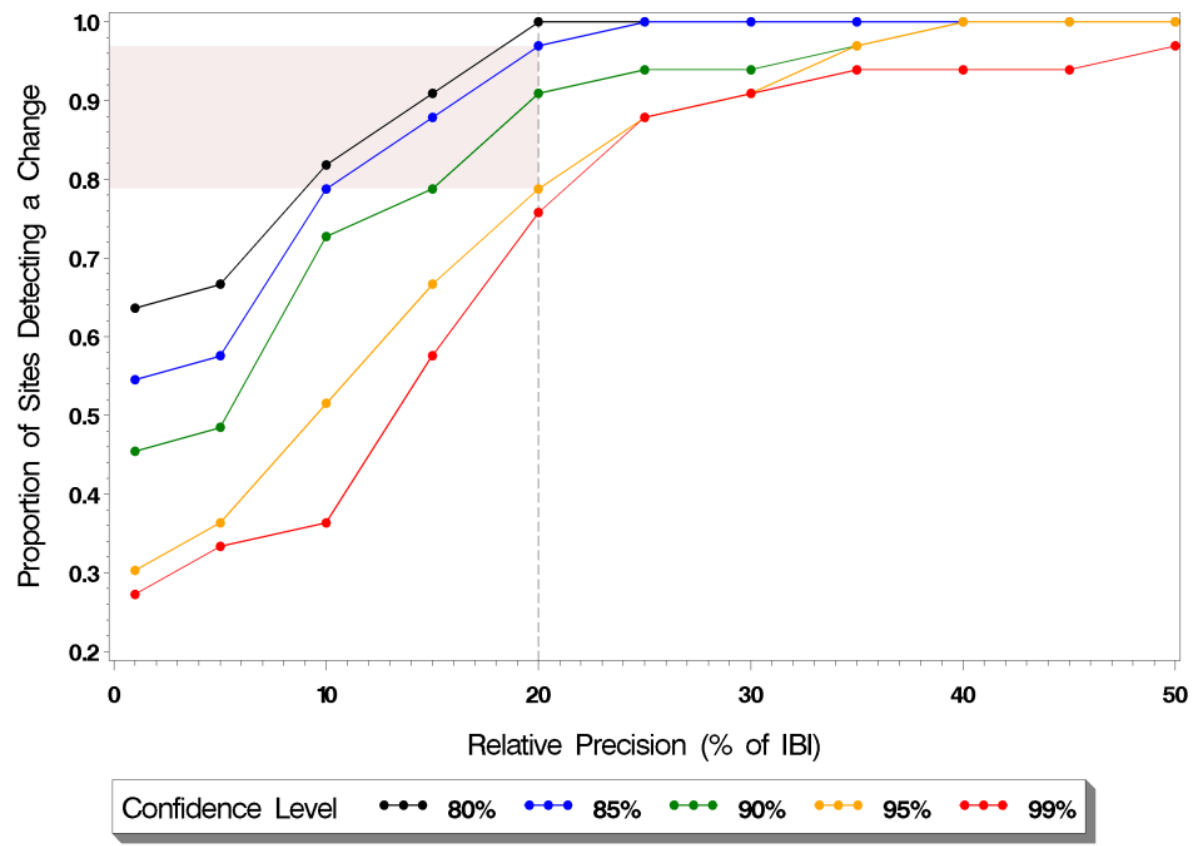

Figure 9. A plot showing the proportion of the 33 invertebrate sites detecting a change in IBI value at varying levels of relative precision (\% of the observed IBI). Five levels of confidence are shown. Gray box indicates the range of site proportions expected given a $20 \%$ change in IBI and $85-95 \%$ confidence.

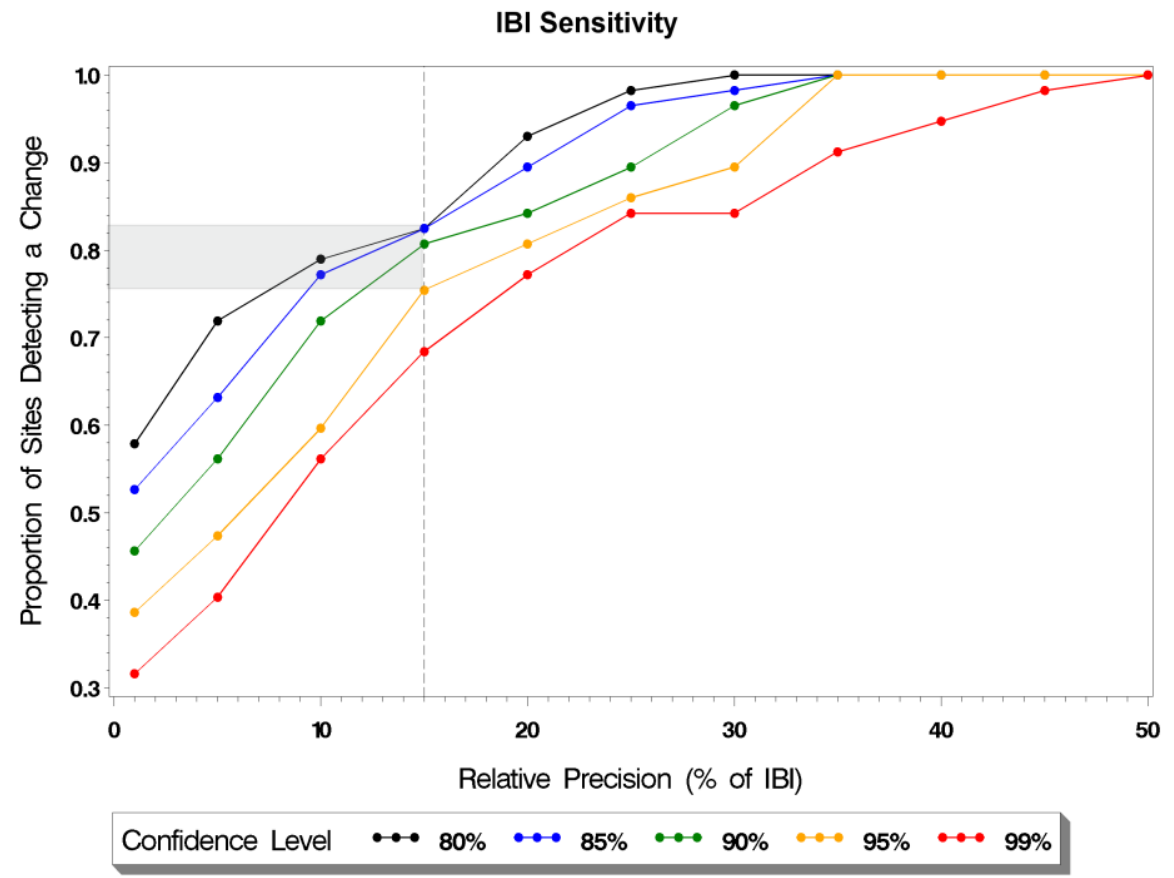

Figure 10. A plot showing the proportion of the 58 avian sites detecting a change in IBI value at varying levels of relative precision (\% of the observed IBI). Five levels of confidence are shown. Gray box indicates the range of site proportions expected given a 15\% change in IBI and 85-95\% confidence. 